\title{
AÇÕES DE CONSCIENTIZAÇÃO AMBIENTAL NO MUNICÍPIO DE TAIOBEIRAS (MG): PERSPECTIVAS E LIMITAÇÕES
}

\author{
Everton Luiz de Paula ${ }^{1}$ \\ Andressa de oliveira Almeida ${ }^{2}$ \\ Fernando Armini Ruela ${ }^{3}$
}

Resumo: A pesquisa "Ações de conscientização ambiental no município de Taiobeiras - MG: perspectivas e limitações" teve como objetivo conhecer o contexto do referido município no âmbito da educação e preservação ambiental. A pesquisa, desenvolvida por meio de um estudo exploratório e de campo, buscou investigar as principais ações realizadas por escolas, prefeituras, órgãos públicos e privados destacando os projetos que envolvem as práticas e ações de conscientização sobre o meio ambiente. $O$ resultado revelou que grande parte das ações não são desenvolvidas por falta de recursos, bem como pelo desinteresse da população com relação às questões ambientais. Dentre as ações identificadas, as que merecem destaque foram as realizadas pelas escolas municipais dado o êxito na abordagem de Educação Ambiental e de sensibilização para preservação dos recursos naturais.

Palavras-chave: Educação Ambiental; Sensibilização; Cidadania.

Abstract: The research "Actions for environmental awareness in the municipality of Taiobeiras - MG: perspectives and limitations" aimed to understand the context of that municipality in the context of environmental education and preservation. The research, developed through an exploratory and field study, sought investigate the main actions carried out by schools, city halls, public and private agencies, highlighting the projects that involve environmental awareness practices and actions. The result revealed that most of the actions are not developed due to lack of resources, as well as lack of interest of the population in relation to environmental issues Among the actions identified, those that deserve to be highlighted were those carried out by municipal schools given the success in the approach of environmental education and awareness raising for the preservation of natural resources.

Keywords: Environmental Education; Awareness; Citizenship.

\footnotetext{
${ }^{1}$ Universidade Federal dos Vales Jequitinhonha e Mucuri . E-mail: everton2804@gmail.com . Link para o Lattes: http://lattes.cnpq.br/7983443176488075

2 Universidade Federal dos Vales Jequitinhonha e Mucuri E-mail: andressadeoliveira_1994@yahoo.com.br. Link para o Lattes: http://lattes.cnpq.br/9420874563531201

3 Universidade Federal dos Vales Jequitinhonha e Mucuri. E-mail: fernando.armini@ufvjm.edu.br. Link para o Lattes: http://lattes.cnpq.br/1044760907479002
} 


\section{Introdução}

A sociedade contemporânea, em uma escala global, vem sofrendo com uma série de conflitos no que diz respeito à interferência humana nos ciclos naturais do planeta. Tais mudanças revelam-se graves e emergenciais, sendo as relações causa-efeito debatidas há anos, tanto na esfera pública quanto na esfera privada. Diante de tantas mudanças, principalmente no clima, a cidade de Taiobeiras não seria exceção. Localizada no Alto Rio Pardo, no norte do estado de Minas Gerais, este município também sofre as consequências das mudanças climáticas, principalmente devido às mudanças nos índices pluviométricos, uma vez que o município depende de um bom regime chuvoso para o desenvolvimento econômico local.

Diante das dificuldades enfrentadas pelo município em relação à escassez hídrica, é necessário refletir sobre como o município está lidando com essas dificuldades e o que está sendo feito para que sejam minimizados os impactos das mudanças climáticas, seja com obras contingenciais ou com a conscientização da população, principal foco deste trabalho.

Em nossa sociedade, a problemática e as diversas questões no âmbito das discussões ambientais sempre foram tratadas sob diferentes prismas sendo que, um dos meios mais eficazes e academicamente aceitos na atualidade para se trabalhar o tema é a conscientização por meio de trabalhos significativos que toquem no tema Educação Ambiental.

Para estruturar e tornar mais significativas as ações de conscientização ambiental e, consequentemente, possibilitar a sensibilização da sociedade em relação aos problemas ambientais, percebe-se a necessidade de ampliação de conceitos no tocante ao termo "ambiente". Em função de sua própria heterogeneidade, esta adequação do conceito ainda permanece ativa no seio da comunidade de estudiosos e apresenta-se para Mendonça (2002, p.125) como um desafio "para toda uma geração de intelectuais, cientistas e ambientalistas que se encontra vinculada a tais discussões no presente e certamente também no futuro próximo". Certamente, uma formulação ideal dos conceitos irá colaborar e permitir a inserção das questões ambientais em definitivo no cotidiano e afazeres dos cidadãos.

Perante uma sociedade cada vez mais consumista, resultado da difusão dos ideais capitalistas de exploração de produtos cada vez mais descartáveis, a percepção do que seja "preservação ambiental" tende a tornar-se cada vez mais míope. Essa visão turva, gravada na mente dos cidadãos, faz com que a relação entre consumo e preservação seja cada vez mais difícil de discernir. Por sua vez, essa dificuldade de discernimento possibilita o surgimento e a difusão de termos e conceitos equivocados que terminam por se camuflarem como ideias que girem em torno da proposta de desenvolvimento sustentável, mas que na prática fogem totalmente à proposta real. 
Um verdadeiro entendimento sobre desenvolvimento sustentável deve, necessariamente, passar pela senda das responsabilidades individual e coletiva. As ações efetivas que tangem o desenvolvimento sustentável assumem que, tanto as responsabilidades individuais quanto às coletivas devem ser interligadas por circunstâncias socioambientais.

Tais responsabilidades exigem, entre outras coisas, a autonomia da população para a participação no debate de políticas públicas como, por exemplo, a qualidade da educação, o empoderamento de pequenos agricultores, a mudança na matriz energética e de transporte, a relação das comunidades locais com o lixo produzido (SORRENTINO, 2005). Tais fatos exemplificam o que as políticas públicas têm que buscar para a integração de sociedade e bens de consumo para melhor convivência e integração.

No estado brasileiro, a política ambiental começou a se fortalecer com a criação da Secretaria Especial do Meio Ambiente (SEMA), em 1973. Em 1981, foi criado o Sistema Nacional do Meio Ambiente (SISNAMA), pela Lei 6.938, que instituiu a Política Nacional do Meio Ambiente (PNMA). Com a promulgação da Constituição Federal de 1988 observa-se um capítulo sobre o Meio Ambiente com a inclusão de medidas mais significativas na área ambiental. O termo Educação Ambiental surgiu no Brasil durante a criação da Política Nacional de Educação Ambiental, Lei $n^{\circ}$ 9795/1999 art. $1^{\circ}$, que a conceituou como os processos por meio dos quais o indivíduo e a coletividade constroem valores sociais, conhecimentos, habilidades, atitudes e competências voltadas para a conservação do meio ambiente, essencial à sadia qualidade de vida e sua sustentabilidade.

Um dos documentos frutos da reformulação e inserção de novas propostas ambientais na constituição e que obteve grande destaque pela abrangência e adoção de práticas de Educação Ambiental mais voltados para a preservação e sensibilização foi a cartilha do Programa Nacional de Educação Ambiental (PRONEA), lançado em 2005 e que é dedicado à divulgação das políticas ambientais. Tais mudanças nesta área só vieram reforçar sua importância ao "promover a Educação Ambiental em todos os níveis de ensino e a conscientização pública para a preservação do meio ambiente" (PRONEA, 2005).

Um dos textos que mais chama a atenção na cartilha do PRONEA é a Carta Aberta dos Educadores, que faz uma dura crítica a modelos fantasiados e que em nada aborda a realidade do que é sustentabilidade. A carta ainda demonstra que deve se deixar de lado os pensamentos financeiros e de exploração que são práticas muito enraizadas na história e na sociedade brasileira.

A execução da Política Nacional de Educação Ambiental está a cargo dos órgãos e entidades integrantes do Sistema Nacional de Meio Ambiente (SISNAMA), das instituições educacionais públicas e privadas dos sistemas de ensino e dos órgãos públicos da União, Estados, Distrito Federal e Municípios, envolvendo entidades não governamentais, entidades de classe,

revista brasileira educação ambiental 
meios de comunicação e demais segmentos da sociedade. Apesar dessa responsabilidade, 0 Estado ausenta-se de assumir seu papel e acaba repassando aos municípios o dever de assumir e inserir a temática. Esses, por sua vez, transferem para o setor da educação a responsabilidade, ficando a cargo dos professores o desenvolvimento de atividades para essa formação ética e ambiental. Essas atividades passam a fazer parte da sala de aula e vão muito além do assunto ecologia e revelam ao aluno sua inserção total no meio em que vive. Percebe-se então que o desafio é o de formular uma Educação Ambiental que seja crítica e inovadora em dois níveis: formal e não formal. Com isso a Educação Ambiental deve ser acima de tudo um ato político, voltado para a transformação social.

Nesse aspecto, ao integrar cidadania e meio ambiente o livro "Educação ou Adestramento Ambiental?" da autora Paula Brugger (BRUGGER,2004), trabalha a problemática e chama a atenção aos modismos sociais. Isso porque, com o crescente número de desastres ambientais, a população não se manifesta, nem procura reavaliar ou mudar suas visões sobre o meio ambiente como algo descartável ou reversível a curto prazo, evidenciando a necessidade de mudança nos valores éticos e morais. Segundo a autora, para transcender a atual crise ambiental é imprescindível a adoção de novos comportamentos e valores, além de novas posturas diante da natureza e nas relações humanas (BRUGGER,2004, p.91).

É necessário destacar que o papel da educação vai muito além de repassar conteúdos, mas de formar cidadãos pensantes, fazendo com que a Educação Ambiental perpasse as diferentes ações do indivíduo. A mesma autora destaca que uma pergunta que deve ser feita é: Educar para que e para quem (BRUGGER, 2004, p.83). Portanto, a Educação Ambiental deve ser trabalhada em toda sociedade, principalmente nas escolas, já que a próxima geração de pessoas ativas inseridas em contexto social e econômico encontra-se na sala de aula.

Nota-se que para mudar essa realidade, que não faz parte apenas do contexto local mas de grande parte das cidades, é necessário refletir como as escolas municipais, prefeituras e demais órgãos públicos e privados ligados ao desenvolvimento rural e urbano trabalham para mudar esse quadro. Assim, este trabalho tem por objetivo analisar as ações em Educação Ambiental em um município na microrregião do Alto Rio Pardo, no norte do estado de Minas Gerais.

A escolha pelo município de Taiobeiras se deve ao fato deste pertencer à mesorregião do norte do estado de Minas Gerais. Essa região é rica em termos culturais porém, problemática em termos socioeconômicos. A região já teve um baixo índice populacional, reflexo de um atraso econômico e social causado por políticas públicas ineficazes e má governança (FRANÇA; SOARES, 2006). Embora seja uma região carente, o poder público até então não vem atuando efetivamente na intensidade em que é desejada. Sendo 
uma região que historicamente já vem sofrendo econômica e socialmente a consequência de mazelas políticas, as atuais mudanças climáticas vêm incrementar o rol de problemas que podem afetar a vida da população. Já na década de 60 , a mesorregião passa a integrar uma área conhecida como "Polígono das Secas", integrando assim o semiárido brasileiro (MOREIRA, 2010).

O município de Taiobeiras está inserido nesta mesorregião e conta com uma atividade agrícola que é de grande importância para a economia do município. Sendo afetado historicamente pelos efeitos da seca e tendo na atividade agrícola seu principal meio de desenvolvimento, o município é, portanto, um bom exemplo de como as mudanças climáticas podem vir a agravar o modo de vida não só da população local, mas também de todo planeta.

\section{Metodologia}

O presente trabalho de pesquisa teve como alvo uma investigação na cidade de Taiobeiras, configurando-se como um trabalho de campo. A proposta principal era desenvolver um estudo enriquecido, buscando informações em escolas, prefeituras e órgãos públicos de como as ações ambientais são desenvolvidas e como influenciam a conscientização ambiental da população. O fluxograma apresentado na Figura 1 (próxima página) resume os passos da pesquisa.

A pesquisa foi iniciada por meio de uma análise de entidades e órgãos (públicos e privados) que realizam atividades voltadas para a adoção de práticas ambientais no município. Feita a pesquisa, o próximo passo foi o contato, via telefone ou e-mail, para a realização de entrevistas. Essas entrevistas foram norteadas por um questionário com perguntas sobre a entidade, bem como sobre as ações de Educação Ambiental que realizam no município. Após o agendamento, os responsáveis das diferentes entidades foram entrevistados, sendo que todos assinaram 0 termo de livre consentimento e esclarecido.

Terminada a fase de entrevistas, a próxima etapa foi a análise das ações desenvolvidas, procurando evidenciar pontos comuns, dificuldades e limitações encontradas no desenvolvimento dessas ações, para em seguida, propor soluções para os problemas evidenciados. 


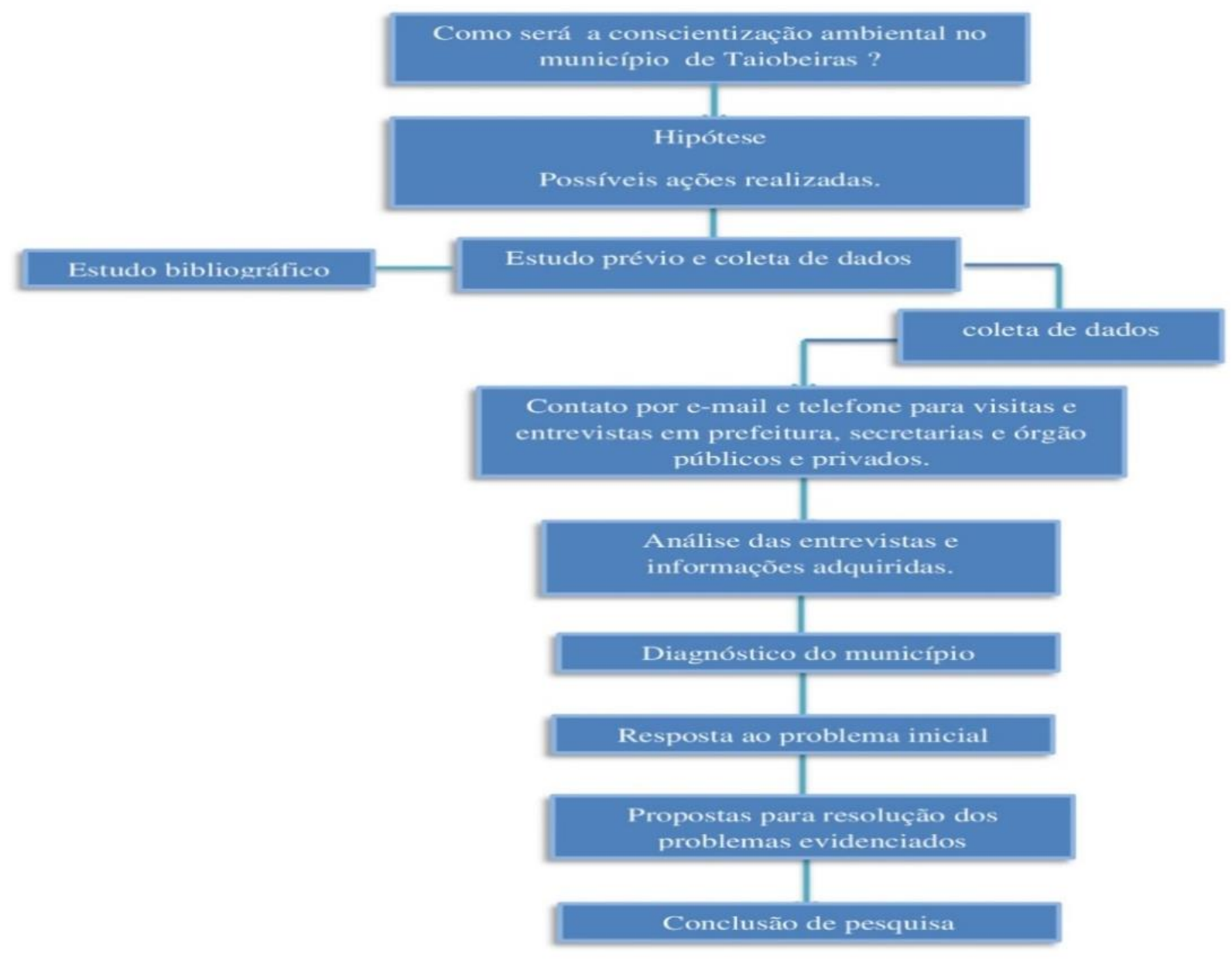

Figura 1: Fluxograma do processo de pesquisa

Fonte: Elaborada pelos autores.

\section{Resultados e discussões}

Conforme destacado anteriormente, o município de Taiobeiras situa-se na microrregião do Alto Rio Pardo ou também chamando Território do Alto Rio Pardo sendo um dos 15 municípios que compõem a microrregião. Sua população atual é estimada pelo IBGE em 30.917 habitantes (IBGE, 2010).

No município de Taiobeiras, as questões ambientais vêm sendo trabalhadas em diversas frentes pelos seguintes órgãos: Conselhos Municipais de Meio Ambiente (CODEMA), Secretaria de Agricultura e Meio Ambiente, Empresa Mineira de Assistência Técnica e Extensão Rural (EMATER), Programa de Educação Ambiental (PROGEA) realizado pela Polícia Miliar de Meio ambiente de Minas Gerais e Escolas Municipais. Além dessas instituições, há ações que são iniciativas baseadas em leis e decretos. 


\section{Análises das ações em cada espaço \\ Ações do CODEMA}

Os Conselhos Municipais de Meio Ambiente (CODEMAs) são criados no âmbito das prefeituras para permitir a participação da sociedade civil, organizações não governamentais, ambientalistas, sindicatos e associações de moradores, universidades e institutos de pesquisa que, em conjunto com instituições públicas, participam na definição e acompanhamento das políticas de preservação e recuperação ambiental no território dos municípios (CODEMA- Regimento Interno Lei Municipal n880 -28/12/2000).

O conselho municipal também é responsável pelas cobranças, penalidades de irregularidade ambientais, desenvolvimento de ações e projetos municipais de mobilização com trabalhos que propõem a conservação e preservação do ambiente, controle de poluição e contaminação, recuperação de reversas legais e Educação Ambiental (CODEMA-Plano Anual de Trabalho 20/11/2015). Com a realização deste trabalho, percebeu-se que a verdadeira realidade deste Conselho é a de um órgão sem recursos financeiros suficientes para a implantação dos planos anuais das atividades sócio-ambientais, restringindo-se a um órgão responsável por fiscalizar licenças ambientais.

\section{Ações da EMATER}

Outra instituição que executa ações relacionadas aos assuntos ambientais é a Empresa Mineira de Assistência Técnica e Extensão Rural (EMATER). Esta instituição não está ligada à gestão municipal e tem como foco de trabalho, o homem do campo. Essa instituição desenvolve palestras educativas como parte de suas ações de extensão rural.

Embora haja limitações, a EMATER desenvolve alguns projetos no município, tal como o "Rio Taboqueiro: renascendo de novo". O Rio Taboqueiro, cuja foto da atual situação é mostrada na Figura 2, é essencial às atividades do município e o projeto surgiu devido à urgente necessidade de salvá-lo.

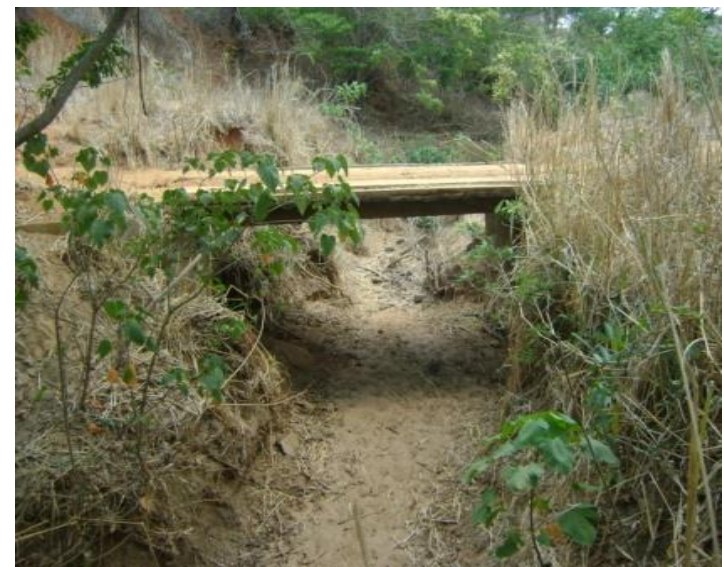

Figura 2: Situação atual do Rio Taboqueiro-Município de Taiobeiras.

Fonte: Emater-Taiobeiras/MG. 
Durante o referido projeto foram executadas atividades de proteção das nascentes, enquanto que a recuperação da mata ciliar não foi realizada, por não haver recursos financeiros. As ações que seriam voltadas à recuperação das matas ciliares acabaram por se limitar em reuniões junto à comunidade, trabalhando-se ações de Educação Ambiental, tema recorrente nas palestras promovidas pela EMATER.

A falta de recursos financeiros para levar informações à população é uma das dificuldades citadas pelos profissionais da EMATER, sendo um reflexo da falta de investimento na área ambiental pelo poder público. No estado, o órgão responsável por coordenar essas ações é a Secretaria de Estado de Meio ambiente e Desenvolvimento Sustentável (SEMAD). Assim como demonstrado na esfera municipal, os objetivos alcançados de forma parcial pela EMATER denunciam o desinteresse que o poder estadual também demonstra com o tema ao não destinar verba suficiente para a realização das ações de "desenvolvimento sustentável" pela instituição em questão.

\section{Ações do PROGEA}

Outra instituição que possui uma preocupação em prol do meio ambiente e que possui uma abordagem no município de Taiobeiras totalmente educativa é a Polícia Militar de Meio ambiente de Minas Gerais. Essa instituição desenvolve o Programa de Educação Ambiental (PROGEA), que tem como objetivo trabalhar em escolas públicas e privadas a conscientização em favor da adoção de comportamento socioambiental adequado e que busque a prevenção ambiental, a sustentabilidade e melhoria da qualidade de vida, além de realizar uma aproximação de crianças e adolescente com a Polícia Militar. A Figura 3 mostra alguns momentos de ações realizados por esse programa.

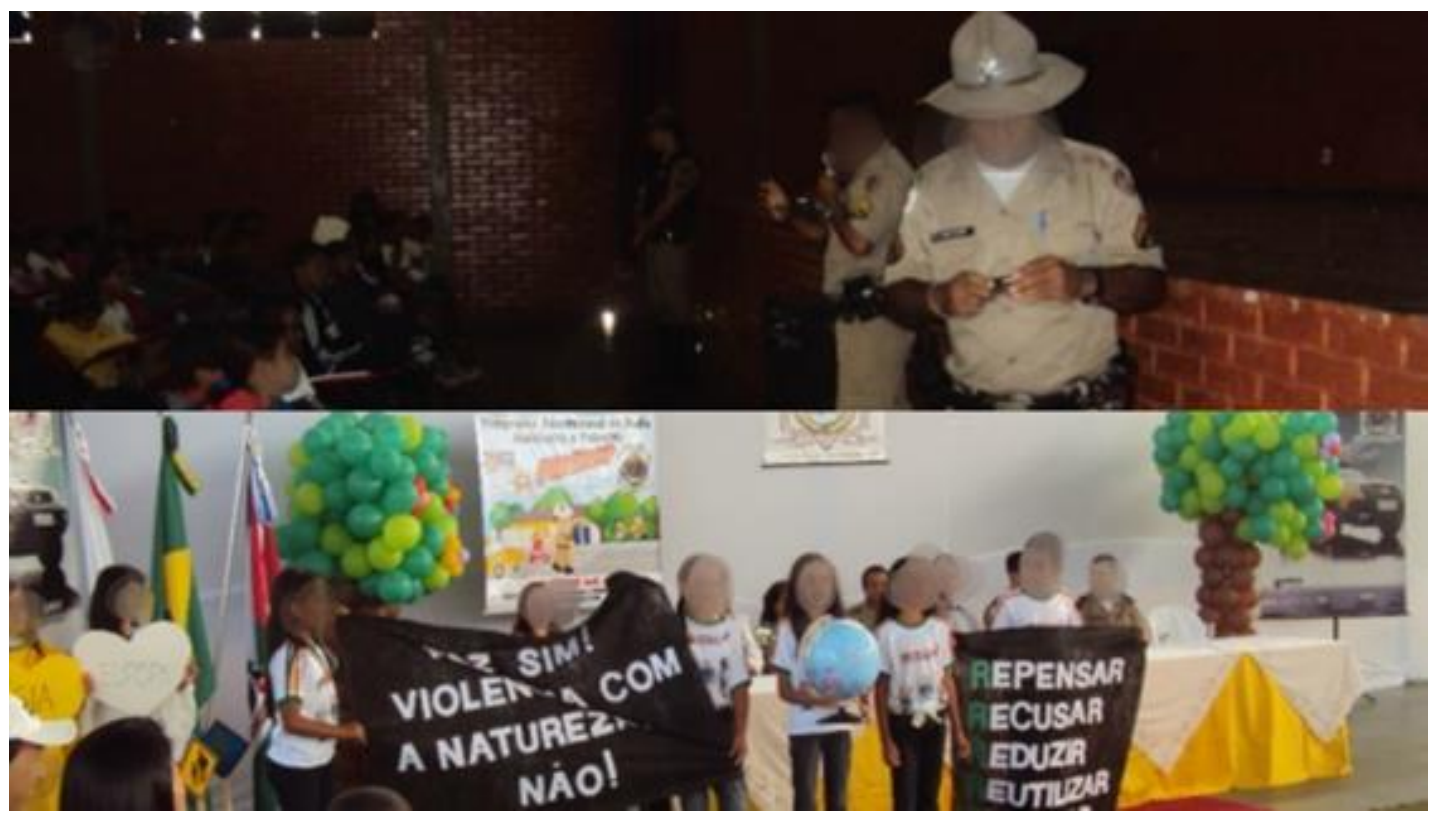

Figura 3: Ação do PROGEA na Escola Municipal João da Cruz Santos. Fonte: Secretaria Municipal de Educação de Taiobeiras. 


\section{Ações de iniciativas baseadas em leis e decretos}

Em Taiobeiras, há iniciativas que se baseiam em leis e decretos. Dessas iniciativas, vale ressaltar o trabalho desenvolvido pela Associação de Catadores de Materiais Recicláveis de Taiobeiras (ASCAMART). A instituição possui um verdadeiro trabalho de intervenção social e ambiental, conquistando - apoio para regulamentação da atividade e se estabelecendo com a construção de um galpão para auxiliar nos trabalhos de seus integrantes, como por exemplo, no auxílio da separação dos materiais recolhidos. A Figura 4 destaca um dos momentos da construção da sede dessa instituição e que muito contribuirá para ações atuais e futuras.

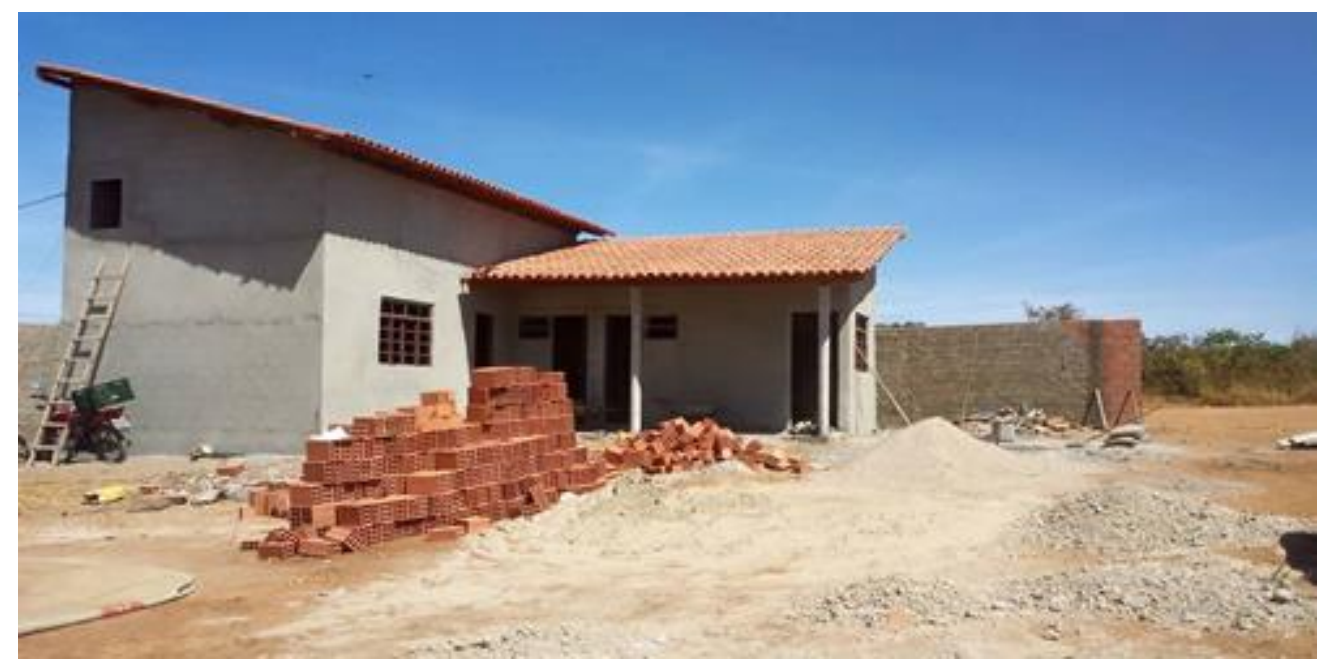

Figura 4: Construção em andamento da sede da ASCAMART.

Fonte: Prefeitura Municipal de Taiobeiras.

Embora seja perceptível o mérito dessa associação, é notável a falta de conhecimento entre a população da necessidade de separação correta dos resíduos das residências. Caso isso acontecesse, o resultado seria uma maior arrecadação de material previamente separado para a associação e como consequência melhor qualidade de vida para as famílias de catadores. Disso deduz-se também a necessidade de maior participação das entidades sociais intervindo e montando uma rede de informações para a divulgação da importância da reciclagem. Uma solução viável, mais simples e sem custos seria o uso das mídias sociais na realização de campanhas educativas e de conscientização.

Outra iniciativa que se baseia em leis e decretos no município é o projeto que prevê o cercamento da nascente Taiobeiras Velha, localizada na zona urbana. Essa ação teria como fruto imediato a melhoria da qualidade de vida, além de enfatizar junto à população a importância de se preservar os recursos naturais. Entretanto, o referido projeto vem se arrastando sem nenhuma perspectiva de ação real visível imediata. Ao consultar o município sobre os impedimentos para o desenvolvimento dessa ação, os órgãos responsáveis 
confirmam a inexistência de recursos e a falta de interesse da população no engajamento às causas ambientais.

\section{Ações em escolas municipais}

Em relação às ações educativas desenvolvidas em escolas, o município de Taiobeiras apresenta grande destaque no assunto Educação Ambiental. O município conquistou um selo UNICEF, resultado de suas efetivas ações no tocante aos assuntos ambientais e pelo esforço das escolas em trabalhar o tema. O projeto que permitiu a conquista do prêmio foi o "Educação para convivência com o semiárido" com desdobramentos do assunto voltado para os problemas das localidades como o do lixo e a preservação da fauna.

O referido projeto envolveu os alunos das Escolas Municipais João da Cruz Santos, João Santana e Tiradentes, contando com apoio de toda comunidade escolar, da Polícia Militar de Meio Ambiente, da Companhia de Saneamento de Minas Gerais (COPASA), EMATER e da ASCAMART, sendo que essa última se manteve com ações contínuas de trabalho e vão muito além da preservação ambiental. Adicionalmente, o projeto concentrou-se com o envolvimento e desenvolvimento de pensamentos voltados para as questões socioambientais, prezando pelo desenvolvimento deste pensamento desde a infância e reiterando a importância de viver e atuar diariamente em condutas ambientais e mostrando-se como dever de todo cidadão.

As Escolas Municipais João da Cruz Santos e João Santana se envolveram com a problemática sobre o lixo, reciclagem e/ou degradação ambiental e propôs trabalhar situações que possibilitassem a comunidade escolar pensar propostas de intervenção na realidade que os cerca, na valorização da vida e, portanto, do meio ambiente. Além disso, a ação configurava-se como uma sistematização do conhecimento, sendo este sempre associado à valorização de uma vida saudável que está intrinsecamente ligada à preservação do meio em que vivem. Para isso, durante a execução do projeto, foi criada uma horta comunitária, garantindo alimentos frescos, livres de agrotóxicos, além de estimular a minimização na produção de resíduos, reciclagem e compostagem.

Os resultados do projeto foram bem expressivos e contaram com o engajamento dos alunos durante todas as atividades. Tal ação acabou por constituir-se em atividade iniciadora e facilitadora, possibilitando às famílias e demais moradores, juntamente com o apoio da COPASA, EMATER e da Prefeitura Municipal, iniciar discussões quanto à canalização de água e valorização da agricultura familiar de maneira sustentável, aliada, em especial, à preservação da fauna e flora. Além disso, parte dos alimentos da horta comunitária foi destinada para distribuição junto às famílias carentes. A Figura 5 resume alguns momentos das ações desse projeto nas diferentes escolas. 


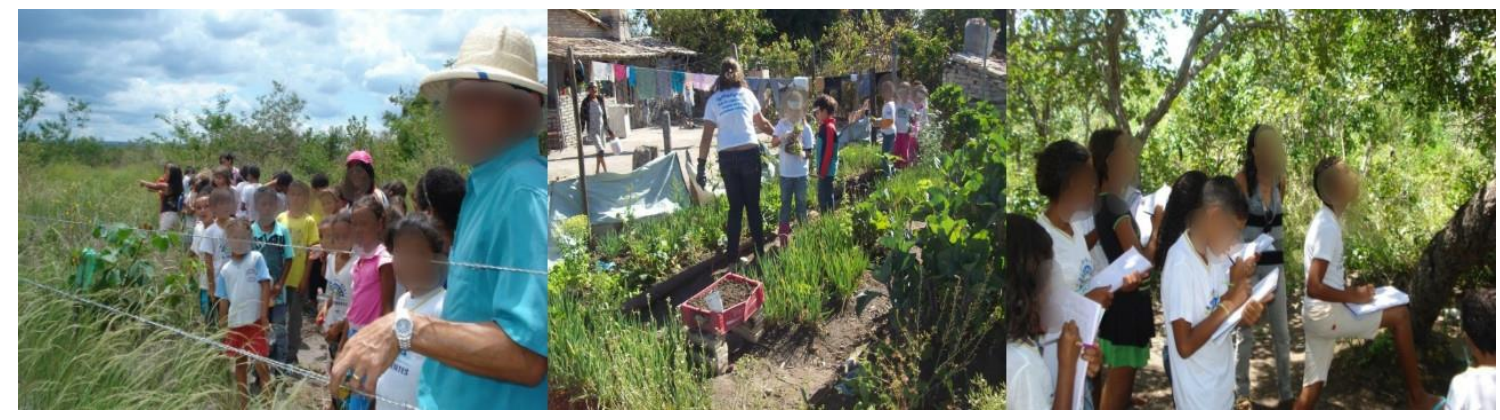

Figura 5: Registro de alguns momentos do projeto "Educação para convivência com o semiárido". Fonte: Secretaria Municipal de Educação de Taiobeiras.

Os projetos desenvolvidos nas três instituições de ensino municipal tiveram a principal função de trabalhar o tema Meio Ambiente contribuindo para a formação de cidadãos conscientes, aptos a decidirem e atuarem em uma realidade socioambiental de modo comprometido. Mais que trabalhar com informações e conceitos, as ações tiveram valor na formação de valores e atitudes e na reflexão sobre a real necessidade de conscientização desta e das gerações futuras.

\section{Considerações finais}

Durante este trabalho observou-se que o tema, embora de importância indiscutível, é possuidor de pouca ou nenhuma disseminação no referido município. Isso é perceptível pelo baixo investimento por parte das políticas públicas e pelo pouco envolvimento dos diversos setores da sociedade em relação ao assunto. Embora haja ações interessantes, esses diferentes programas e ações existentes no município ocorrem quase sempre sem recursos financeiros expressivos e contam quase exclusivamente com a dedicação de alguns envolvidos que entendem mais profundamente a seriedade da questão e que se propõem a desenvolver até o seu término.

Além disso, as ações ocorrem de forma isolada e sem um planejamento mais apurado, o que pode resultar em riscos de comprometimento de eficiência durante execução e, por conseguinte refletir também em ações deficitárias quanto aos seus objetivos propostos.

De fato, a única ação que realmente teve participação efetiva e integração entre diversos setores foi aquela desenvolvida nas escolas municipais citadas, demonstrando maior estruturação do projeto e maior envolvimento das instituições, setores e indivíduos. Como prova de que projetos e ações devidamente estruturadas e conduzidas geram melhores resultados, o projeto "Educação para convivência com o semiárido" conquistou um selo da UNICEF, como resultado de suas efetivas ações educativas no tocante aos assuntos ambientais. Vê-se, portanto, que ações de conscientização ambiental desenvolvidas nas escolas podem trazer resultados 
satisfatórios, uma vez que os envolvidos podem replicar o conhecimento e desenvolver ações ambientalmente sustentáveis em seu cotidiano.

O principal fator que impede à ideal condução dos projetos e ações propostas é a falta de recursos financeiros. Tal fato resultou quase sempre em desenvolvimento de uma metodologia abaixo da qualidade em termos de estruturação, considerando os objetivos que seus idealizadores realmente pretendiam. Dessa forma, projetos e ações dessa natureza não tiveram oportunidade de realização de testes prévios para inferir aplicabilidade e adequação segundo as reais demandas da localidade.

Tendo em vista que a questão financeira é o principal limitador no desenvolvimento das ações das diferentes entidades, uma primeira ação que poderia ser desenvolvida para supri-la seria a captação, via projetos, de recursos do setor privado. Isso porque, grandes corporações destinam parte dos seus recursos para realização de projetos relacionados ao meio ambiente. Assim, como as instituições do município já desenvolvem tais ações e possuem conhecimento dos problemas a serem enfrentados, a empresa que disponibilizasse o recurso seria uma grande aliada na preservação ambiental do município.

Uma segunda proposta para vencer o obstáculo da falta de recurso é a participação de editais de fomento de órgão públicos: agências, como o Conselho Nacional de Desenvolvimento Científico e Tecnológico (CNPQ) e Coordenação de Aperfeiçoamento de Pessoal (CAPES) sempre publicam editais voltados para o desenvolvimento de projetos para a preservação ambiental. As instituições neste caso necessitariam se organizar frente aos prazos e elaborar projetos que poderiam ser submetidos para a apreciação destes e de outros órgãos de fomento.

Por último e não menos importante, uma terceira proposta para superar a falta de investimento é por meio de parcerias. As associações e órgãos que muitas vezes não conseguem desenvolver seu trabalho de forma isolada, poderiam se unir e realizar ações conjuntas e que necessariamente não precisassem de altos investimentos. É possível, por exemplo, realizar campanhas educativas e de conscientização por meio das mídias sociais, sem utilizar recursos financeiros, apenas humanos das instituições.

Em suma, o município de Taiobeiras vem demonstrando atuação nos assuntos ligados à conscientização ambiental. Entretanto, ainda é urgente a necessidade dos projetos e ações serem tratados com mais seriedade em todas as esferas do poder público e no seio da população. O pouco interesse sobre 0 assunto reflete a falta de consciência sobre a necessidade de preservação ambiental e da busca por atividades econômicas realmente sustentáveis que ainda são latentes na sociedade. 


\section{Referências}

BRUGGER, P. Educação ou adestramento ambiental? $3^{\text {a }}$ edição. Florianópolis/SC. Editoras Letras Contemporâneas. 2004

CARNEIRO, M.G.T. ; FERREIRA, R.C.T. Educação Ambiental: Que Critérios Adotar Para Avaliar A Adequação Pedagógica De Seus Projetos?. Ciência \& Educação. Piracicaba, 2001. 10 p. Disponível: <http://arquivos.ambiente.sp. gov.br/cea/cea/Texto avaliacao ea.pdf>. Acesso em: 2 Mar. 2017.

CARVALHO, I.C.M.; GRÜN, M.; TRAJBER, R. Pensar o Ambiente: bases filosóficas para a Educação Ambiental. Brasília: Ministério da Educação, Secretaria de Educação Continuada, Alfabetização e Diversidade, UNESCO, 2006.

CODEMA-Conselho Municipal de Desenvolvimento Ambiental. Plano Anual de Trabalho do Fundo Municipal de meio ambiente (FUMMA) e contêm outras Providencias. 20/11/2015.Taiobeiras/MG.

CODEMA-Conselho Municipal de Desenvolvimento Ambiental. Regimento Interno Aprovado 13/02/2001. Taiobeiras/MG.

EMATER. Projeto: Rio Taboqueiro renascendo de novo. Taiobeiras, 2009.

FRANÇA, I. S.; SOARES, B.R. O sertão norte mineiro e suas transformações recentes. In: Encontro de Grupos de Pesquisa 2., 2006, Uberlândia. Anais...Uberlândia: Universidade Federal de Uberlândia, 2006. p. 1-15.

GUIMARÃES, M.N; VASCONCELLOS, M.M. Relações entre Educação Ambiental e educação em ciências na complementaridade dos espaços formais e não formais de educação. Educar, Editora UFPR, Curitiba, 2006. 12 p.

GOUVÊA, R.G.R.. Rumos da formação de professores para a Educação Ambiental. Educar, Curitiba, n. 27, p. 163-179, 2006.

IBGE. Censo 2010. Disponível em <https://cidades.ibge.gov.br/brasil/mg/ taiobeiras/panorama> Acesso em 28 fev.2017.

JACOBI, P.R. Educação Ambiental, Cidadania E Sustentabilidade. Cadernos de Pesquisa, n. 118, p. 189-205, março/ 2003.

JACOBI , P.R. Educação Ambiental: o desafio da construção de um pensamento crítico, complexo e reflexivo. Educação e Pesquisa, São Paulo, v. 31, n. 2, p. 233-250, maio/ago. 2005.

LOUREIRO, B.; FREDERICO, C. Complexidade E Dialética: Contribuições À Práxis Política e Emancipatória em Educação Ambiental. Educ. Soc., Campinas, vol. 26, n. 93, p. 147314 ..

MENDONÇA, F. Geografia socioambiental. In: MENDONÇA, F.; KOZEL, S. (Orgs.). Elementos de epistemologia da geografia contemporânea. Curitiba: UFPR, 2002. p. 121-144

MINISTÉRIO DE MEIO AMBIENTE-MINISTÉRIO DA EDUCAÇÃO. Programa Nacional de Educação Ambiental - Pronea. Brasília, v. 3, 2005. p105. 
MORAES, S.R.R. et al. Visão Geral Dos Problemas E Da Política Ambiental no Brasil. Informações Econômicas, São Paulo, v.34, n.4, abr. 2004.

MOREIRA,H. F. Se for Morrer de Fome eu Prefiro Morrer de Tiro: O Norte de Minas e a formação de lideranças rurais. 2010 139f. Dissertação (Mestrado) - Programa de Pós-Graduação de Ciências Sociais em Desenvolvimento, Agricultura e Sociedade, Universidade Federal Rural do Rio de Janeiro, Rio de Janeiro, 2010.

PAINEL DE DEBATES SOBRE EDUCAÇÃO AMBIENTAL - Os desafios atuais da Educação Ambiental no contexto nacional. Ministério do Meio Ambiente.. ICMBIO, 2013. Video (26).

PELEGRINI, D.F.; VLACH, V.R.F. As múltiplas dimensões da Educação Ambiental: por uma ampliação da abordagem. Revista Sociedade e Natureza. Uberlândia, ano 23 n. 2, 187-196, maio/ago. 2011.

SORRENTINO, M.; TRAJBER, R.; FERRARO-JUNIOR, L.A. Educação Ambiental Como Política Pública. Educação e Pesquisa, São Paulo, v. 31, n. 2, p. 285-299, maio/ago. 2005.

TRISTÃO, M. Tecendo Os Fios Da Educação Ambiental: O Subjetivo E O Coletivo, O Pensado E O Vivido. Universidade Federal Do Espírito Santo. Educação e Pesquisa, São Paulo, v. 31, n. 2, p. 251-264, maio/ago. 2005

VASCONCELLOS, H.S.R. et al. Espaços Educativos Impulsionadores Da Educação Ambiental. Cad. Cedes, Campinas, vol. 29, n. 77, p. 29-47, 2009. 